\title{
Review Article \\ Pediatric Traumatic Brain Injury and Autism: Elucidating Shared Mechanisms
}

\author{
Rahul Singh, ${ }^{1}$ Ryan C. Turner, ${ }^{1}$ Linda Nguyen, ${ }^{2}$ Kartik Motwani, ${ }^{3}$ \\ Michelle Swatek, ${ }^{4}$ and Brandon P. Lucke-Wold ${ }^{1}$ \\ ${ }^{1}$ Department of Neurosurgery, West Virginia University School of Medicine, Morgantown, WV 26505, USA \\ ${ }^{2}$ Department of Basic Pharmaceutical Sciences, West Virginia University School of Medicine, Morgantown, WV 26505, USA \\ ${ }^{3}$ Department of Medical Sciences, University of Florida School of Medicine, Gainesville, FL 32611, USA \\ ${ }^{4}$ Department of Psychology, North Carolina State University, Raleigh, NC 27695, USA
}

Correspondence should be addressed to Brandon P. Lucke-Wold; bwold@mix.wvu.edu

Received 2 October 2016; Accepted 23 November 2016

Academic Editor: Akin Ojagbemi

Copyright (C) 2016 Rahul Singh et al. This is an open access article distributed under the Creative Commons Attribution License, which permits unrestricted use, distribution, and reproduction in any medium, provided the original work is properly cited.

Pediatric traumatic brain injury (TBI) and autism spectrum disorder (ASD) are two serious conditions that affect youth. Recent data, both preclinical and clinical, show that pediatric TBI and ASD share not only similar symptoms but also some of the same biologic mechanisms that cause these symptoms. Prominent symptoms for both disorders include gastrointestinal problems, learning difficulties, seizures, and sensory processing disruption. In this review, we highlight some of these shared mechanisms in order to discuss potential treatment options that might be applied for each condition. We discuss potential therapeutic and pharmacologic options as well as potential novel drug targets. Furthermore, we highlight advances in understanding of brain circuitry that is being propelled by improved imaging modalities. Going forward, advanced imaging will help in diagnosis and treatment planning strategies for pediatric patients. Lessons from each field can be applied to design better and more rigorous trials that can be used to improve guidelines for pediatric patients suffering from TBI or ASD.

\section{Introduction}

Awareness about autism spectrum disorder (ASD) has continued to increase over the past few years. One in 110 eight year olds were on the spectrum in the United States in 2006, which increased to one in 68 children on the spectrum in 2010 based on data collected from the Autism and Developmental Disabilities Monitoring (ADDM) Network [1]. The percentage of males affected is much higher than females with some variability between studies [2]. Although the number of patients diagnosed with autism has increased, it is unclear if this is actually due to an increased prevalence or reflective of changes in diagnostic criteria, as the physiologic changes underlying this disease are not well characterized [1]. Recent evidence suggests that cerebellar injury can contribute to autism development [3]. Other causes of ASD such as obstetric complications and neonatal jaundice have also been reported in the literature but are not the focus of this paper. Interestingly, the number of reported cases for several different types of pediatric traumatic brain injury (TBI) has been increasing during this time period as well [4]. Is it possible that moderate-to-severe TBI leads to damage that is rewiring circuits? What is currently known about the shared mechanisms between moderate-to-severe TBI and autism? Can lessons from management of each be used to develop better treatment options? In this review, we discuss what is currently known about the shared mechanisms between moderate-to-severe pediatric TBI and ASD and highlight the importance of advanced imaging to answer these important questions.

\section{Disorders}

The Office of Special Education started collecting data for TBI as a disability category in the same year that it began collecting data for ASD. The prevalence of both ASD and TBI among successive births of US school-aged children showed a marked increase in the period between 1992 and 2001 [5]. Cohort curves suggest that these two disorders exhibit similar increases in prevalence over that period. 
TBI from nonaccidental head injury may lead to substantial neurological and developmental deficits. A small study of children who suffered nonaccidental head injury (due to intentional abrupt impact or violent shaking) showed speech and language difficulties consistent with a diagnosis of ASD [6].

The sequelae of TBI in children include deficits in intelligence, memory, attention, learning, and social judgment [7]. Family and twin studies investigating ASD show that risk is determined by genetic factors. However, environmental insults including TBI may also contribute to risk of developing ASD [8]. Changes to areas in the brain associated with communication that are observed in TBI patients have also been noted in children diagnosed with ASD [9]. Ozgen and colleagues examined external morphological features in a large population sample of children with ASD versus normal controls. The results showed a high prevalence of morphological abnormalities in the patients with ASD without mental retardation but did not address the cause of these abnormalities [8]. Minor anomalies and major abnormalities are common variants significantly more prevalent in children diagnosed with ASD or TBI compared to normal controls [10]. Males showed a trend for more abnormalities than females. Males have increased risk of TBI, which can potentially predispose to these morphological anomalies [11].

2.1. Natural Progression of Pediatric TBI. Children with TBI must be identified and treated in a timely manner in order to limit secondary brain injury and improve outcomes. Initial assessment of any traumatic injury patient begins with completion of the primary survey and stabilization of potentially fatal conditions related to airway, breathing, and circulation [12]. This is followed by a secondary survey that includes a neurological assessment [12].

The Glasgow Coma Scale (GCS) is a grading system used to assess consciousness and thus grade the severity of TBI by stratifying the sum of three tests: verbal, eye, and motor responses [51]. The GCS describes the severity of TBI as follows: mild (GCS 13-15), moderate (GCS score of 9-12), and severe (GCS score of 8 or less) [51]. Since its inception, the original GCS has been modified for use in children [52].

Neurologically intact patients with a GCS of 14 or greater may be discharged home under the supervision of a responsible adult with instructions on discharge to seek immediate medical care in the event of worsening headaches or signs of neurological injury. Pediatric patients with a GCS of less than 13 should undergo a computed tomography scan to evaluate traumatic intracranial injury and be admitted [53].

Patients with an intracranial hemorrhage without significant mass effect should be admitted to the pediatric intensive care unit for close monitoring. An intracranial pressure monitor should be placed in patients with severe TBI and a poor GCS score to evaluate intracranial hypertension [54]. Intracranial hypertension reflects a sustained increase in intracranial pressure and warrants intervention. Initial management should focus on conservative measures such as optimizing head position to ensure adequate venous outflow, ensuring adequate pain control and sedation [12]. Further escalation of care would involve administering hyperosmolar therapy, mild hyperventilation, and CSF diversion with a ventriculostomy drain [12].

Patients with intracranial hypertension refractory to the aforementioned therapies may benefit from a craniotomy to evacuate a hematoma or a decompressive craniectomy [55]. Surgical treatment should also be considered in patients with subdural, epidural, or intraparenchymal hematomas or posterior fossa mass lesions with associated mass effect [56, 57].

2.2. Important Considerations for Autism. Children with autism display unusual responses to environmental stimuli (e.g., loud sounds), problems making friends, difficulty understanding nonverbal social cues, blunted response to pain, and a focus on geometric patterns. The diagnosis of autism is often delayed despite the fact that parents often note concerning behavior by 18 months of age and less than $10 \%$ of children are diagnosed at initial presentation $[58,59]$. A qualitative impairment in social interaction and communication as well as the presence of repetitive and stereotypic actions must be present for a diagnosis of autism [59]. Patients with autism often exhibit profound anxiety and this is exacerbated in the setting of traumatic injury [13]. Strategies to reduce anxiety include social stories and the use of games for distraction, as well as using favorite drinks to disguise medications. It is helpful to have a discussion with parents to help identify what may exacerbate or mollify anxiety in patients with autism [17].

2.3. Shared Symptoms. TBI and ASD share similar deficits in neurodevelopmental abilities and social dysfunction (Table 1). Because of this link in symptoms between TBI and ASD, novel treatment approaches used to regain social judgment and communication skills in ASD patients may be applicable to TBI patients. In 2007, Radice-Neumann and colleagues reviewed the long-term effects of TBI focusing on emotional and interpersonal relationship deficits. Following TBI, many areas of functioning are impaired: emotional decision-making, self-regulatory behavior, emotional perception difficulties, and facial affect recognition [13]. Neuroanatomical changes that occur with TBI can result in deficits of facial recognition [13]. These are the same deficits that define ASD. This suggests that interventions, which are currently standard of practice for ASD, can be incorporated into the treatment paradigm for TBI patients to increase their social function and improve quality of life. We discuss a few of these interventions in a later section.

An impairment of language is a cardinal feature in the diagnosis of ASD. Not surprisingly, neural activation during language tasks is altered following moderate-to-severe TBI in young children as well. Interestingly, genetic studies show susceptibility of certain individuals to brain injury and the subsequent impairment of language [60]. A small feasibility study of 8 children with TBI and 12 matched controls used fMRI imaging to define the network of brain region deficits following TBI [15]. They examined differences in neural activation during a language task in children with TBI relative to a matched group of children with orthopedic injuries. Performance status on standardized language tasks as well as 
TABLE 1: Shared behavioral symptoms between ASD and pediatric TBI.

\begin{tabular}{|c|c|c|c|}
\hline Symptom & ASD & Pediatric TBI & Refs \\
\hline ADHD & $\mathrm{X}$ & & [13] \\
\hline Anxiety/stress & $\mathrm{X}$ & $\mathrm{X}$ & {$[13]$} \\
\hline Balance/coordination & $\mathrm{X}$ & $\mathrm{X}$ & {$[14]$} \\
\hline Communication deficits & $\mathrm{dx}$ & $\mathrm{X}$ & {$[15]$} \\
\hline Depression & & $\mathrm{X}^{*}$ & {$[13]$} \\
\hline Emotional-empathy lacking & & $\mathrm{X}$ & {$[13]$} \\
\hline Emotional dysregulation & & $\mathrm{X}$ & [13] \\
\hline Emotional recognition & $\mathrm{X}$ & $\mathrm{X}^{*}$ & {$[13]$} \\
\hline Executive function impaired & $\mathrm{X}$ & $\mathrm{X}$ & {$[16]$} \\
\hline Family relationships & & $\mathrm{X}$ & {$[13]$} \\
\hline Headaches & & $\mathrm{X}$ & {$[12]$} \\
\hline Language deficits/delays & $\mathrm{dx}$ & $\mathrm{X}$ & {$[17]$} \\
\hline Mental retardation & $\mathrm{X}$ & & {$[11]$} \\
\hline Repetitive behaviors & $\mathrm{dx}$ & & {$[3]$} \\
\hline Restricted Interests & $\mathrm{dx}$ & & {$[18]$} \\
\hline Seizures & $\mathrm{X}$ & $\mathrm{X}$ & [19] \\
\hline $\begin{array}{l}\text { Self-regulation behavior } \\
\text { impaired }\end{array}$ & $\mathrm{X}$ & $\mathrm{X}$ & {$[13]$} \\
\hline Sensory dysfunction & $\mathrm{dx}$ & & {$[20]$} \\
\hline Social-loneliness and isolation & & $\mathrm{X}$ & {$[21]$} \\
\hline Social interaction/skills & $\mathrm{dx}$ & $\mathrm{X}$ & [13] \\
\hline
\end{tabular}

$\mathrm{X}$ : highly prevalent; $\mathrm{dx}$ : part of diagnostic criteria; $*$ : greatest area of deficit in TBI.

activation patterns in language circuitry centers allowed the researchers to make conclusions about the concise areas of brain damage. Activation was noted to differ in the patients with TBI for the right superior temporal gyrus (BA22) and the right middle temporal gyrus (BA21). The data analyzed supports that a child's brain function differs significantly following TBI and that language task dysfunction may be reflective of differences in neuropsychological task performance [15]. This suggests that cortical reorganization in children after TBI may be similar to the clinical presentation seen with ASD. The deficits in each may have similar neural underpinnings.

Executive function relating to social skills, language, and attention is decreased in children diagnosed with ASD. Studies examining deficits in executive function as it relates to location and severity of cerebral damage in children after TBI have produced mixed results [16]. Power and colleagues investigated the effects of location and severity of a lesion on executive function in early childhood TBI patients evaluating neuroimaging and clinical report measures for 36 patients. They were able to identify functional deficits regarding inhibitory control, including self-monitoring and self-regulation. These functional deficits were observed in all subjects with TBI, regardless of location or the site of damage [16]. Self-regulation deficits were also observed within groups for those diagnosed with ASD. Additional research is necessary to further evaluate the developmental progression of children who have suffered TBI in early childhood years.

\section{Shared Biochemical Mechanisms}

There are several mechanisms of nervous system dysregulation present in both autism and pediatric TBI which may contribute to similar symptoms present in both diseases. These common manifestations encompass gastrointestinal disorders, learning difficulties, seizures, and difficulties in sensory processing [14]. Further work is needed to delineate symptom manifestations between children diagnosed with ASD and those experiencing TBI. A likely reason for the difficulty in diagnosis is that both ASD and TBI share similar comorbidities [61]. Because of these comorbidities, it becomes increasingly important to investigate shared mechanisms that lead to symptom manifestations.

3.1. Gastrointestinal Disorders. A prominent area of ongoing research is disruption of the enteric nervous system. ASD is frequently associated with decreased viability of traditional gut microflora [62]. The connections defining the gut-brain axis fail to form correctly in some autistic individuals [63]. Without sufficient diversity of microflora in the intestines, the brain does not receive appropriate feedback and development is hindered [64]. In pediatric TBI, global metabolism is slowed leading to decreased survivability of microflora [65]. The underlying cause of microflora demise is partly mediated by the release of high mobility group box 1 protein from necrotic tissue in the intestines [66]. The release triggers a cytokine storm, which causes an inflammatory cascade [67]. The inflammatory cascade leads to increased permeability in the intestine, which further exacerbates the microbiome disruption [68]. To offset this sudden loss of microflora diversity, probiotic therapy has been administered with success in some individuals [69]. Future work is needed to elucidate if the microbiome is similar or different between children diagnosed with ASD compared to those experiencing TBI.

3.2. Learning Difficulties. It is well known that a subset of children diagnosed with ASD have severe learning difficulties [70]. The underlying cause has been postulated as a deficit in cortical plasticity mechanisms [18]. Additionally, poor communication skills limit the child from receiving adequate social feedback necessary for learning [71]. The learning deficits in children with ASD are therefore multifactorial and depend on both deficits in attention processing as well as the inability to attend to salient stimuli [72]. At a molecular level, neuroligin deficits contribute to decreased long-term potentiation in children with ASD [73]. TBI similarly disrupts the learning cascade by increasing attention deficits [74]. Not surprisingly, working-memory processing speed in children is also slowed following TBI [75]. The molecular process for pediatric TBI is based heavily upon the activation of secondary injury cascades following acute blood brain barrier disruption [76]. These cascades damage neuronal tissue forcing the brain to rewire in order to compensate [77]. How this rewiring contributes to permanent learning disability has yet to be elucidated but warrants further investigation especially in the context of ASD. 
3.3. Seizures. Abnormal gray and white matter volume distribution is common in autism [19]. It is likely that this disrupted development contributes to epileptic activity. In a mouse autism model, astroglial glutamate transporter deficiency led to increased seizure activity [78]. Similarly, a downregulation of Pten phosphatase triggered hyperexcitability within the temporal cortex [79]. Seizure is also common following TBI in children. Approximately $12 \%$ of children experience seizure following moderate TBI [80]. The use of animal models has shown that dysfunction in lipid peroxidation contributes to the generation of epileptic foci [81]. Ultimately, structural damage leads to abnormal neurological findings [82]. In both autism and posttraumatic epilepsy, overactivation of the phosphatidylinositol-3-kinase/AKT pathway contributes to cellular mutations in epileptic regions [83]. Early life seizures can cause learning disabilities throughout life [84]. Understanding the mechanics of morphologic development may aid in improving treatment options for seizure in children with autism or who experience TBI [85].

3.4. Sensory Processing Disruption. For children with ASD, over $90 \%$ experience some type of sensory processing disruption [20]. The most common are visual and auditory [86]. The majority of these sensory disruptions are due to prolonged event-related potentials [87]. These prolonged potentials lead to delayed stimulus response latency [88]. Mouse studies have shown that these prolonged potentials may be due to loss of MeCP2 function [89]. Similarly, loss of Gabrb3 gene signaling is associated with deficits in sensory processing [90]. Post-TBI changes in plasticity can also lead to sensory processing deficits [91]. The sensory processing deficits observed following TBI are statistically different compared to the normal range seen in noninjured children [92]. Ongoing preclinical and clinical studies must be performed to determine the underlying causes of these deficits following TBI. It is likely that the deficits are closely related to location of injury, but it has yet to be determined whether they are due to prolonged event-related potentials as seen with ASD or due to another independent mechanism.

\section{Advanced Imaging Correlations}

4.1. Imaging for Autism. Functional magnetic resonance imaging (fMRI) has been used to determine functional connectivity for patients with ASD. Glerean and colleagues found both hypo- and hyperconnectivity in the ventrotemporallimbic subnetwork. This system rewiring accounts for distinct connectivity differences compared to normotypical controls [93].

Additionally, diffusion-weighted MRI in ASD patients revealed increased anisotropy in the caudate and decreased signaling in the superior temporal pole, further supporting the idea of disconnectivity in patients with ASD [94]. Similarly, anisotropy is decreased in the internal capsule, corpus callosum, and cerebellum, indicating white matter damage [95]. Not surprisingly, children with ASD also have a decreased myelin water fraction [96]. This decreased axonal water fraction may indicate axonal injury and has been linked to decreased extra-axonal diffusivity [97].
Recently, it has been shown that disruption between the subcortical region and sensory cortical centers can lead to behavior disruptions such as poor social communication, behavioral inflexibility, and atypical sensory processing [98]. Going forward, it is essential that further research be conducted to link structural differences to functional changes in behavior.

4.2. Imaging for Pediatric TBI. Diffusion tensor imaging (DTI) has shown that children with acute injury have decreased fractional anisotropy indicating white matter disruption similar to that seen in ASD [99]. These deficits have been linked to decreased sensory processing speeds and rewiring of circuitry [100]. Metabolomic studies have provided even further evidence of white matter disruption. The NAA/creatine and NAA/choline ratios were significantly reduced in white matter tracts following injury and were associated with significant cognitive dysfunction [101]. MRI has been used to show significant atrophy of the corpus callosum after injury, but whether this atrophy is due to axonal shearing or loss of myelin integrity is unknown [102]. Magnetization transfer imaging can be used to determine changes in the myelin integrity, but its use is still experimental and warrants further investigation [103].

Similar to ASD, sensory processing is a primary concern for pediatric TBI patients. Susceptibility weighted imaging (SWI) has been used to determine the expected behavioral dysfunction, decreased social interaction, and intellectual performance that is to be expected after injury [104]. When SWI is used concurrently with DTI, adequate detection of acute hemorrhage and diffuse axonal injury can be obtained [105]. Axonal injury can contribute to impaired sensory integration, which can be detected through visual and auditory exams [106]. Not surprisingly, Galvin and colleagues reported that the majority of children score outside the range of typical sensory processing when administered a sensory profile following TBI [92]. Future investigation will examine how biomarkers correlate with functional changes observed on imaging and behavioral changes detected on exam. Korley and colleagues found significant serum changes of brainderived neurotrophic factor in children with functional imaging changes following TBI indicating increased susceptibility for depression [107]. Further studies are necessary to determine if sensory processing deficits are linked to changes in mood.

\section{Behavioral Treatment Approaches}

5.1. Autism. Applied behavioral analysis (ABA) is one of the most effective ways to help children with ASD [108]. B. F. Skinner originally targeted the application of ABA to help with the verbal aspect of behavior, but over time the approach has evolved to deal with the multiple deficits seen in ASD [109]. The purpose of ABA is to redirect a behavior that would be seen as unacceptable or harmful to a behavior that is something both useful and beneficial for the child with autism [110]. It is most successful when started at a young age because it can be used to redirect negative behaviors before they become lifetime habits [108]. ABA has many adaptive arms that address specialty situations such 
as social awkwardness, sensory overloads, and aphasia [111]. $\mathrm{ABA}$ benefits from echoic learning requiring the participant to verbalize what is heard. Through this process, the child builds upon repetitive intraverbalizations and over time puts emphasis on a given response to a nonverbal stimulus. Eventually, the child learns to ask for wants and needs contingent upon an extrinsic reinforcer [112]. This progressive learning process is very important in the treatment of verbal dysfunction associated with ASD but can also be applied to other behaviors such as attention and learning.

While ABA is the most widely used treatment for ASD, other therapy techniques are emerging [108]. The pivotal response therapy is an early-stage intervention tactic emphasizing a response to multiple cues. Similar to ABA, the older the child is at start of treatment, the harder it becomes to break habits that have already been conditioned for long periods of time [113]. Pivotal response therapy is an ongoing therapy and must be used at continuous intervals. The main focus of pivotal therapy is to adjust how parents and children respond to the multiple environmental cues that are part of their everyday lives. Pivotal therapy is practiced when the child is in his or her natural environment rather than a clinical setting offering an advantage over traditional approaches by enhancing motivation [114]. Another frequently used treatment is verbal behavior therapy. Verbal behavior therapy focuses on improving aspects related to the quality and expression of language. The primary goal is to help rewire connections in the brain to improve language understanding. By understanding language, the child is able to use it for effective communication [109]. These therapies are often used in conjunction with ABA to enhance child responsiveness [113].

5.2. Pediatric TBI. Because pediatric TBI produces similar deficits to those seen in ASD, ABA has recently been utilized to readapt children to their home environment after injury [115]. As was the case with ASD, the earlier the therapy is initiated, the more likely it will be effective [109]. For children suffering severe TBI, the benefit of therapy is progressive and behavior can continue to improve at extended time points [115]. ABA is multidimensional and can be used to target social interactions, communication, and activities of daily living [21]. Additionally, pivotal response therapy can be used in conjunction with ABA to allow the child to respond in the environmental setting that best suits him or her. It places less stress on the child and allows for him or her to receive the proper attention that might be needed following a severe TBI [116]. Similar to ABA, pivotal response therapies provide incremental stepwise improvements over time for TBI patients. These improvements are best maintained with multitherapy treatment approaches [117].

\section{Pharmacologic Treatment Approaches}

6.1. Autism. Though many theories on the origins of autism have been put forth and specific brain regions have been consistently implicated in the past decades, the etiology of autism remains largely elusive because many cases arise from a mixture of multiple environmental and genetic factors [118,
119]. Hence, many current interventions target the secondary behavioral symptoms of autism [120]. These targeted symptoms include insomnia, anxiety, depression, mood swings, agitation, repetitive motor behaviors, obsessive-compulsive symptoms, impulsivity, hyperactivity, aggression, and selfinjurious behavior. No medications are currently available that directly impact the core social and cognitive impairments.

6.2. Neuroleptic Agents. Risperidone and aripiprazole are the only two US FDA-approved medications for autism and specifically for only the treatment of irritability, such as aggression, self-injurious behavior, temper tantrums, and mood swings [118, 121]. Risperidone is approved for patients that are at least five years old. It is an atypical antipsychotic that acts as an antagonist of both dopamine $\left(\mathrm{D}_{2}\right)$ and serotonin $\left(5 \mathrm{HT}_{2 \mathrm{~A}}\right.$ and others) receptors $[122,123]$. Adverse events associated with risperidone use include including weight gain, increased appetite, fatigue, drowsiness, drooling, tremor, and constipation [118, 124-127].

Aripiprazole is approved for ages six and up. It is also an atypical antipsychotic drug, impacting the dopamine and serotonin systems. Distinct from risperidone, which is a potent $\mathrm{D}_{2}$ antagonist, aripiprazole may act as $\mathrm{D}_{2}$ agonist, partial agonist, or antagonist depending on cellular location of $\mathrm{D}_{2}$ receptor [128]. This theory of functional selectivity confers aripiprazole the unique ability to be a dopamine agonist where levels are too low and a dopamine antagonist where levels are too high [129]. Because of its unique mechanism of action, aripiprazole may have a more favorable side-effect profile compared to risperidone [130]. Mild and transient effects such as sedation, drooling, tremors, and weight gain were noted in patients taking aripiprazole [131].

6.3. Selective Reuptake Inhibitors (SRI). In autistic individuals, anxiety and repetitive and ritualistic behavior can hinder social interaction and learning [132, 133]. SRIs in general are effective in treating anxiety and obsessive-compulsive symptoms [134, 135]. In addition, accumulating evidence shows that serotonin system abnormalities may contribute to the etiology of autism [136-139]. Consequently, these agents have been increasingly used in treating the disruptive behaviors in autistic individuals [140, 141]. A recent metaanalysis of the published literature provides support for a small but significant effect of SRI in the treatment of repetitive behaviors in ASD [140]. There is also some evidence to suggest that SRIs may be helpful for the proper management of comorbid anxiety in ASD [141]. However, to date, the clinical trials examining the use of SRIs in autism have been mostly limited by small sample sizes and mixed results, warranting the need for additional randomized controlled trials.

6.4. Other Therapies. At the neurochemical level, apart from dopamine and serotonin, abnormalities in a number of other key neurotransmitters and/or receptors have been implicated. This includes glutamate [142], GABA [143], the neuropeptide oxytocin [144-146], and nicotinic acetylcholine receptors $[147,148]$ (Table 2). 


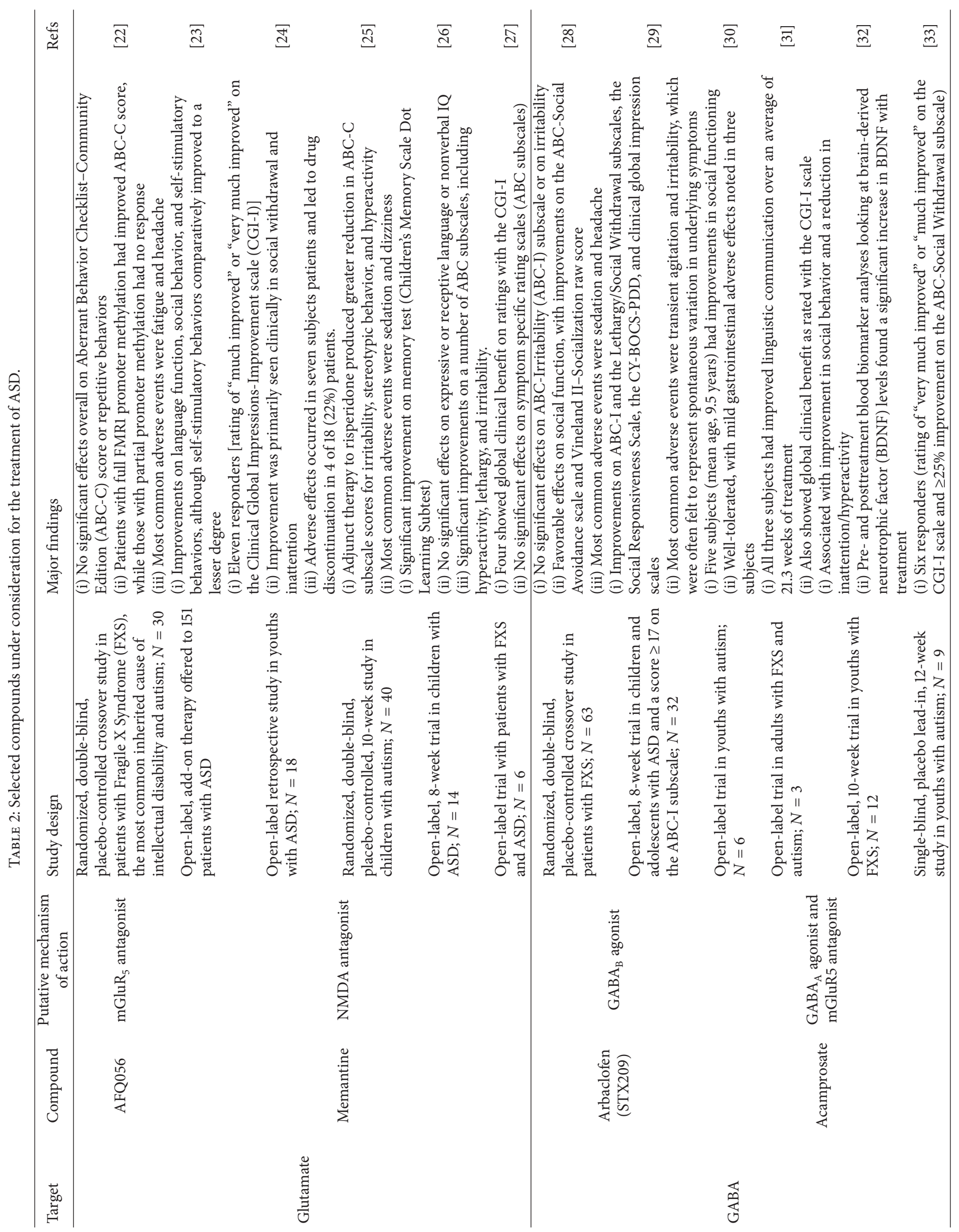




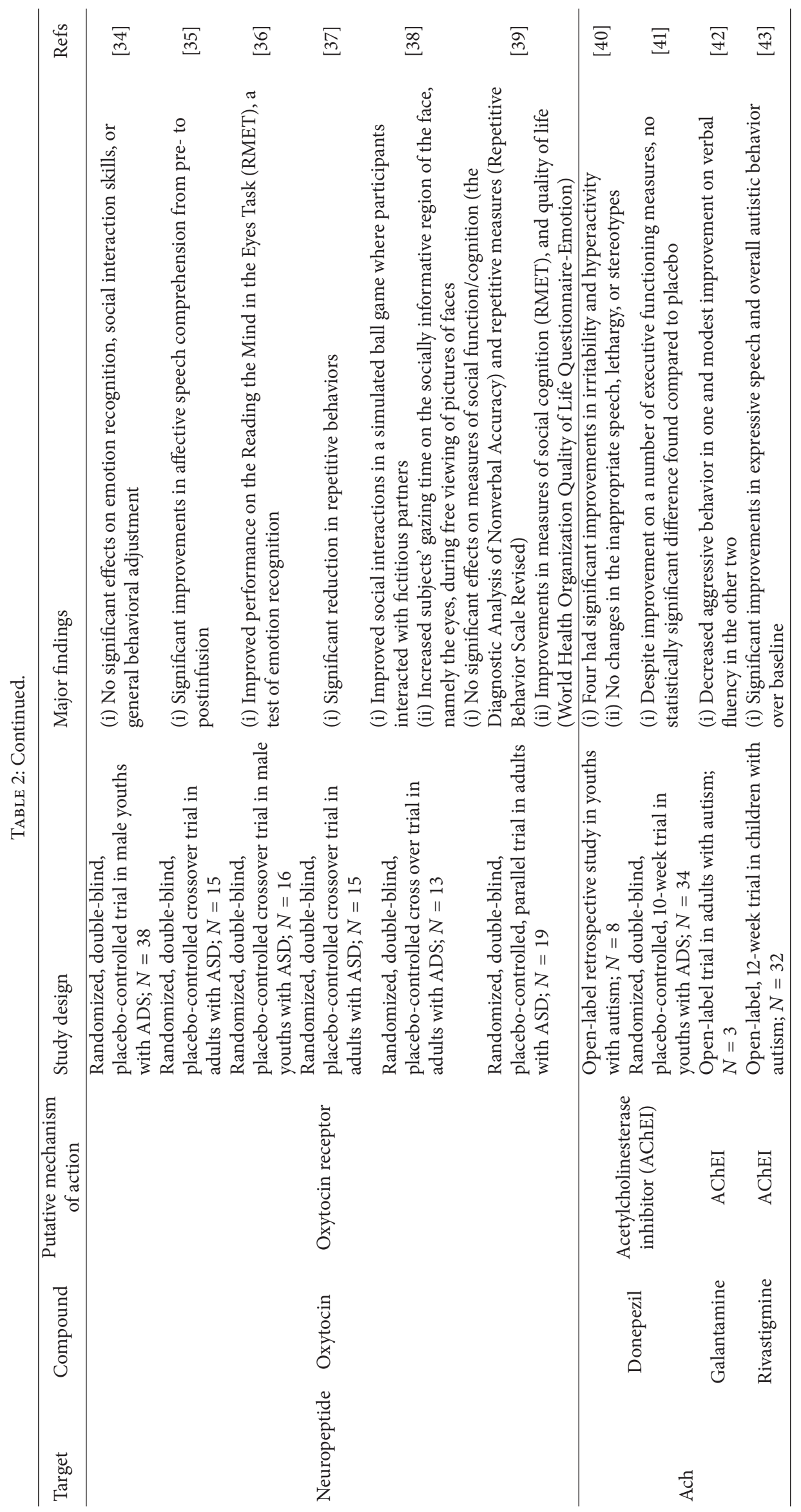




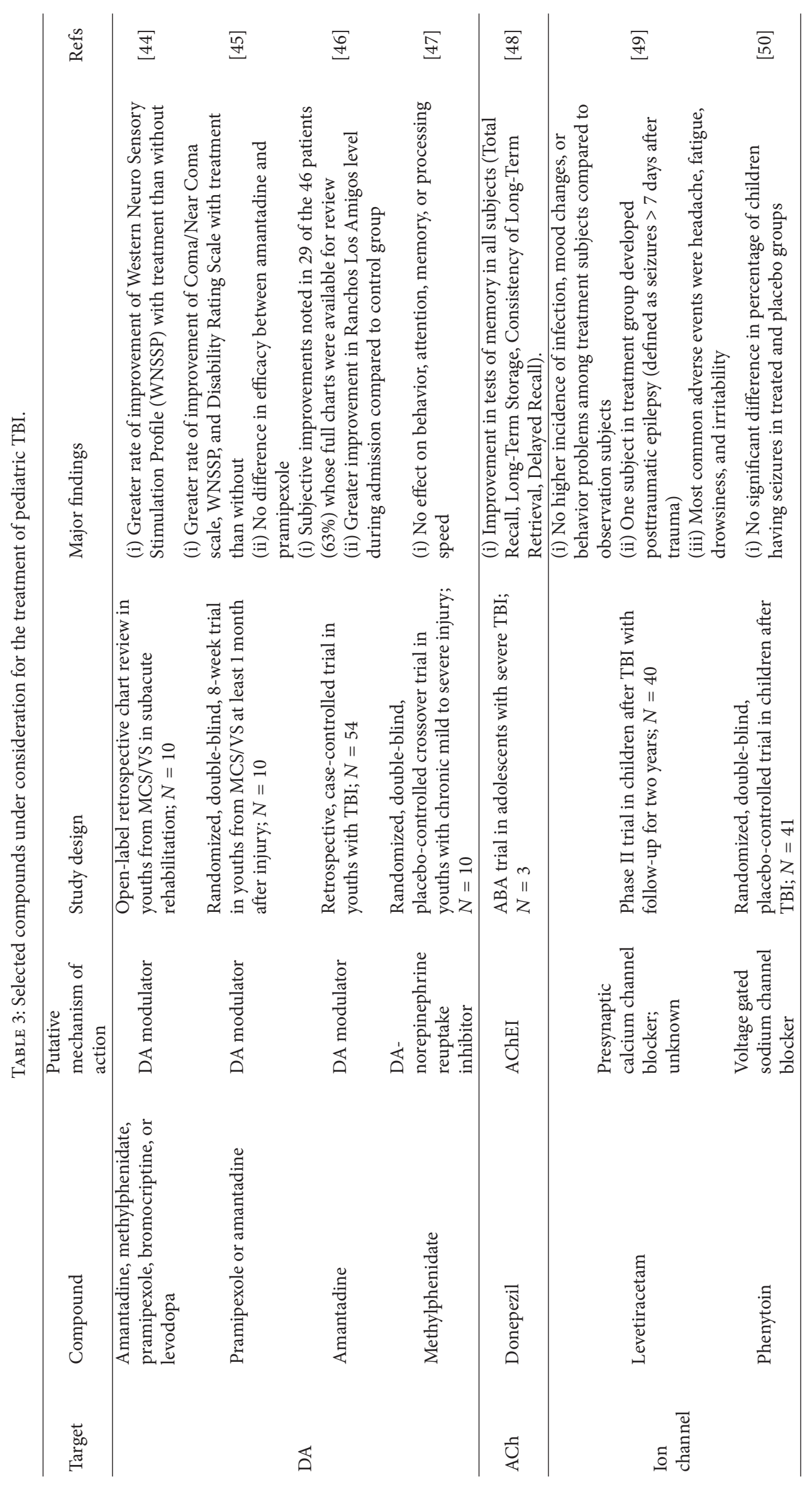


6.5. Pediatric TBI. TBI can result in a variety of neurological and behavioral disturbances, including seizures, impulsivity, and cognitive decline. In recent years, there has been a rapid increase in the number of pharmacological targets evaluated in various animal models of TBI, many with significant positive outcomes. Unfortunately, their proven efficacy in the clinical setting are still lacking for both the adult and pediatric population $[149,150]$. Table 3 summarizes selected clinical studies examining the therapeutic potential of pharmaceutical agents following pediatric TBI. With an increased understanding of the cellular and molecular mechanisms underlying the pathophysiological events after TBI, however, hope remains regarding the development of novel pharmaceutical therapies to better address the longterm patient outcomes [151].

6.6. Future Directions. No single agent likely will become the "magic bullet" in treating pediatric TBI and autism. As for pharmacologic research for the neurological sequela following TBI and the core symptoms of autism advances, a greater emphasis on a holistic approach, combining behavioral and pharmacologic therapy, may emerge. Currently, the only empirically supported behavioral treatments for autism are based on ABA [108], which has been combined with pharmacologic treatment in at least one trial [152]. In this study, the combination of an atypical antipsychotic and parent training resulted in greater reduction of serious maladaptive behavior than medication alone in children with ASD [152]. No studies, to our knowledge, have been conducted in adults or children following TBI using this combined therapy approach. In addition to combined pharmacology and behavioral therapy, it may be advantageous to use a polypharmacy approach and/or a drug with multiple and pleiotropic mechanism due to the complexity and heterogeneity present in TBI and autism $[120,153]$.

\section{Conclusions}

Children diagnosed with ASD or suffering pediatric TBI share similar symptoms based on pathophysiologic changes within the brain. In this review, we discussed several shared symptoms including dysfunction in communication, loss of executive function, and deficits in memory and intellectual processing. Not surprisingly, pediatric TBI patients and ASD patients share several underlying pathophysiologic changes that contribute to these symptoms and cause increased susceptibility for sensory processing dysfunction, seizures, and gastrointestinal disorders. Advanced imaging modalities are being used to track changes within the brain related to symptom manifestations. The similarities between TBI and ASD warrant continued investigation and improved classification criteria. Treatment approaches including ABA and pharmacologic agents may benefit patients with pediatric TBI or ASD. Future work will delineate the subtle differences between these spectrum disorders.

\section{Disclosure}

Equal contribution for first author is denoted.

\section{Competing Interests}

No competing interests are reported.

\section{Acknowledgments}

Brandon Lucke-Wold was supported by a Neurosurgery Research and Education Foundation Grant, American Foundation of Pharmaceutical Education Grant, Sigma Xi Grants in Aid of Research Grant, and American Medical Association Foundation Seed Grant. The authors would like to thank Paula Webster for her advice on the relevant autism spectrum disorder literature.

\section{References}

[1] K. Weintraub, “The prevalence puzzle: autism counts," Nature, vol. 479, no. 7371, pp. 22-24, 2011.

[2] M.-C. Lai, M. V. Lombardo, and S. Baron-Cohen, "Autism," The Lancet, vol. 383, no. 9920, pp. 896-910, 2014.

[3] S. S.-H. Wang, A. D. Kloth, and A. Badura, "The cerebellum, sensitive periods, and autism," Neuron, vol. 83, no. 3, pp. 518532, 2014.

[4] K. Bakker, C. Catroppa, and V. Anderson, "Olfactory dysfunction in pediatric traumatic brain injury: a systematic review," Journal of Neurotrauma, vol. 31, no. 4, pp. 308-314, 2014.

[5] C. J. Newschaffer, L. A. Croen, J. Daniels et al., "The epidemiology of autism spectrum disorders," Annual Review of Public Health, vol. 28, pp. 235-258, 2007.

[6] K. Barlow, E. Thompson, D. Johnson, and R. A. Minns, "The neurological outcome of non-accidental head injury," Pediatric Rehabilitation, vol. 7, no. 3, pp. 195-203, 2004.

[7] R. L. Peterson, A. K. Connery, D. A. Baker, and M. W. Kirkwood, "Preinjury emotional-behavioral functioning of children with lingering problems after mild traumatic brain injury," Journal of Neuropsychiatry and Clinical Neurosciences, vol. 27, no. 4, pp. 280-286, 2015.

[8] H. Ozgen, G. S. Hellemann, R. K. Stellato et al., "Morphological features in children with autism spectrum disorders: a matched case-control study," Journal of Autism and Developmental Disorders, vol. 41, no. 1, pp. 23-31, 2011.

[9] A. B. Brown and J. H. Elder, "Communication in autism spectrum disorder: a guide for pediatric nurses," Pediatric Nursing, vol. 40, no. 5, pp. 219-225, 2014.

[10] K. F. Linton and B. J. Kim, “Traumatic brain injury as a result of violence in native American and black communities spanning from childhood to older adulthood," Brain Injury, vol. 28, no. 8, pp. 1076-1081, 2014.

[11] N. C. Collins, M. Molcho, P. Carney et al., "Are boys and girls that different? An analysis of traumatic brain injury in children," Emergency Medicine Journal, vol. 30, no. 8, pp. 675-678, 2013.

[12] Brain Trauma Foundation, American Association of Neurological Surgeons, and Congress of Neurological Surgeons, "Guidelines for the management of severe traumatic brain injury," Journal of Neurotrauma, vol. 24, supplement 1, pp. S1S106, 2007.

[13] D. Radice-Neumann, B. Zupan, D. R. Babbage, and B. Willer, "Overview of impaired facial affect recognition in persons with traumatic brain injury," Brain Injury, vol. 21, no. 8, pp. 807-816, 2007. 
[14] S. Gorman, M. A. Barnes, P. R. Swank, M. Prasad, and L. EwingCobbs, "The effects of pediatric traumatic brain injury on verbal and visual-spatial working memory," Journal of the International Neuropsychological Society, vol. 18, no. 1, pp. 29-38, 2012.

[15] P. R. Karunanayaka, S. K. Holland, W. Yuan et al., "Neural substrate differences in language networks and associated language-related behavioral impairments in children with TBI: a preliminary fMRI investigation," NeuroRehabilitation, vol. 22, no. 5, pp. 355-369, 2007.

[16] T. Power, C. Catroppa, L. Coleman, M. Ditchfield, and V. Anderson, "Do lesion site and severity predict deficits in attentional control after preschool traumatic brain injury (TBI)?" Brain Injury, vol. 21, no. 3, pp. 279-292, 2007.

[17] N. Taghizadeh, A. Davidson, K. Williams, and D. Story, "Autism spectrum disorder (ASD) and its perioperative management," Paediatric Anaesthesia, vol. 25, no. 11, pp. 1076-1084, 2015.

[18] B. A. Church, C. L. Rice, A. Dovgopoly et al., "Learning, plasticity, and atypical generalization in children with autism," Psychonomic Bulletin and Review, vol. 22, no. 5, pp. 1342-1348, 2015.

[19] K. Blackmon, "Structural MRI biomarkers of shared pathogenesis in autism spectrum disorder and epilepsy," Epilepsy and Behavior, vol. 47, pp. 172-182, 2015.

[20] Y.-S. Chang, J. P. Owen, S. S. Desai et al., "Autism and sensory processing disorders: shared white matter disruption in sensory pathways but divergent connectivity in social-emotional pathways," PLOS ONE, vol. 9, no. 7, Article ID e103038, 2014.

[21] M. Spreckley and R. Boyd, "Efficacy of applied behavioral intervention in preschool children with autism for improving cognitive, language, and adaptive behavior: a systematic review and meta-analysis," Journal of Pediatrics, vol. 154, no. 3, pp. 338$344,2009$.

[22] S. Jacquemont, A. Curie, V. des Portes et al., "Epigenetic modification of the FMR1 gene in fragile X syndrome is associated with differential response to the mGluR5 antagonist AFQ056," Science Translational Medicine, vol. 3, no. 64, Article ID 64ral, 2011.

[23] M. G. Chez, Q. Burton, T. Dowling, M. Chang, P. Khanna, and C. Kramer, "Memantine as adjunctive therapy in children diagnosed with autistic spectrum disorders: an observation of initial clinical response and maintenance tolerability," Journal of Child Neurology, vol. 22, no. 5, pp. 574-579, 2007.

[24] C. A. Erickson, D. J. Posey, K. A. Stigler, J. Mullett, A. R. Katschke, and C. J. McDougle, "A retrospective study of memantine in children and adolescents with pervasive developmental disorders," Psychopharmacology, vol. 191, no. 1, pp. 141147, 2007.

[25] A. Ghaleiha, M. Asadabadi, M.-R. Mohammadi et al., "Memantine as adjunctive treatment to risperidone in children with autistic disorder: a randomized, double-blind, placebocontrolled trial," International Journal of Neuropsychopharmacology, vol. 16, no. 4, pp. 783-789, 2013.

[26] T. Owley, J. Salt, S. Guter et al., "A prospective, open-label trial of memantine in the treatment of cognitive, behavioral, and memory dysfunction in pervasive developmental disorders," Journal of Child and Adolescent Psychopharmacology, vol. 16, no. 5, pp. 517-524, 2006.

[27] C. A. Erickson, J. E. Mullett, and C. J. McDougle, "Openlabel memantine in fragile X syndrome," Journal of Autism and Developmental Disorders, vol. 39, no. 12, pp. 1629-1635, 2009.

[28] E. M. Berry-Kravis, D. Hessl, B. Rathmell et al., "Effects of STX209 (Arbaclofen) on neurobehavioral function in children and adults with fragile $\mathrm{X}$ syndrome: a randomized, controlled, phase 2 trial," Science Translational Medicine, vol. 4, no. 152, Article ID 152ra127, 2012.

[29] C. A. Erickson, J. M. Veenstra-Vanderweele, R. D. Melmed et al., "STX209 (Arbaclofen) for autism spectrum disorders: an 8week open-label study," Journal of Autism and Developmental Disorders, vol. 44, no. 4, pp. 958-964, 2014.

[30] C. A. Erickson, M. Early, K. A. Stigler, L. K. Wink, J. E. Mullett, and C. J. McDougle, "An open-label naturalistic pilot study of acamprosate in youth with autistic disorder," Journal of Child and Adolescent Psychopharmacology, vol. 21, no. 6, pp. 565-569, 2011.

[31] C. A. Erickson, J. E. Mullett, and C. J. McDougle, "Brief report: acamprosate in fragile X syndrome," Journal of Autism and Developmental Disorders, vol. 40, no. 11, pp. 1412-1416, 2010.

[32] C. A. Erickson, L. K. Wink, B. Ray et al., "Impact of acamprosate on behavior and brain-derived neurotrophic factor: an openlabel study in youth with fragile X syndrome," Psychopharmacology, vol. 228, no. 1, pp. 75-84, 2013.

[33] C. A. Erickson, L. K. Wink, M. C. Early et al., "Brief report: pilot single-blind placebo lead-in study of acamprosate in youth with autistic disorder," Journal of Autism and Developmental Disorders, vol. 44, no. 4, pp. 981-987, 2014.

[34] M. R. Dadds, E. MacDonald, A. Cauchi, K. Williams, F. Levy, and J. Brennan, "Nasal oxytocin for social deficits in childhood autism: a randomized controlled trial," Journal of Autism and Developmental Disorders, vol. 44, no. 3, pp. 521-531, 2014.

[35] E. Hollander, J. Bartz, W. Chaplin et al., "Oxytocin increases retention of social cognition in autism," Biological Psychiatry, vol. 61, no. 4, pp. 498-503, 2007.

[36] A. J. Guastella, S. L. Einfeld, K. M. Gray et al., "Intranasal oxytocin improves emotion recognition for youth with autism spectrum disorders," Biological Psychiatry, vol. 67, no. 7, pp. 692694, 2010.

[37] E. Hollander, S. Novotny, M. Hanratty et al., "Oxytocin infusion reduces repetitive behaviors in adults with autistic and Asperger's disorders," Neuropsychopharmacology, vol. 28, no. 1, pp. 193-198, 2003.

[38] E. Andari, J.-R. Duhamel, T. Zalla, E. Herbrecht, M. Leboyer, and A. Sirigu, "Promoting social behavior with oxytocin in high-functioning autism spectrum disorders," Proceedings of the National Academy of Sciences of the United States of America, vol. 107, no. 9, pp. 4389-4394, 2010.

[39] E. Anagnostou, L. Soorya, W. Chaplin et al., "Intranasal oxytocin versus placebo in the treatment of adults with autism spectrum disorders: a randomized controlled trial," Molecular Autism, vol. 3, article no. 16, 2012.

[40] A. Y. Hardan and B. L. Handen, "A retrospective open trial of adjunctive donepezil in children and adolescents with autistic disorder," Journal of Child and Adolescent Psychopharmacology, vol. 12, no. 3, pp. 237-241, 2002.

[41] B. L. Handen, C. R. Johnson, S. McAuliffe-Bellin, P. J. Murray, and A. Y. Hardan, "Safety and efficacy of donepezil in children and adolescents with autism: neuropsychological measures," Journal of Child and Adolescent Psychopharmacology, vol. 21, no. 1, pp. 43-50, 2011.

[42] M. Hertzman, "Galantamine in the treatment of adult autism: a report of three clinical cases," The International Journal of Psychiatry in Medicine, vol. 33, no. 4, pp. 395-398, 2003.

[43] M. G. Chez, M. Aimonovitch, T. Buchanan, S. Mrazek, and R. J. Tremb, "Treating autistic spectrum disorders in children: utility 
of the cholinesterase inhibitor rivastigmine tartrate," Journal of Child Neurology, vol. 19, no. 3, pp. 165-169, 2004.

[44] P. D. Patrick, M. L. Buck, M. R. Conaway, and J. A. Blackman, "The use of dopamine enhancing medications with children in low response states following brain injury," Brain Injury, vol. 17, no. 6, pp. 497-506, 2003.

[45] P. D. Patrick, J. A. Blackman, J. L. Mabry, M. L. Buck, M. J. Gurka, and M. R. Conaway, "Dopamine agonist therapy in lowresponse children following traumatic brain injury," Journal of Child Neurology, vol. 21, no. 10, pp. 879-885, 2006.

[46] L. B. Green, J. E. Hornyak, and E. A. Hurvitz, "Amantadine in pediatric patients with traumatic brain injury: a retrospective, case-controlled study," American Journal of Physical Medicine and Rehabilitation, vol. 83, no. 12, pp. 893-897, 2004.

[47] S. E. Williams, M. D. Ris, R. Ayyangar, B. K. Schefft, and D. Berch, "Recovery in pediatric brain injury: is psychostimulant medication beneficial?" Journal of Head Trauma Rehabilitation, vol. 13, no. 3, pp. 73-81, 1998.

[48] M. Trovato, B. Slomine, F. Pidcock, and J. Christensen, "The efficacy of donepezil hydrochloride on memory functioning in three adolescents with severe traumatic brain injury," Brain Injury, vol. 20, no. 3, pp. 339-343, 2006.

[49] P. L. Pearl, R. McCarter, C. L. McGavin et al., "Results of phase II levetiracetam trial following acute head injury in children at risk for posttraumatic epilepsy," Epilepsia, vol. 54, no. 9, pp. e135e137, 2013.

[50] B. Young, R. P. Rapp, J. A. Norton, D. Haack, and J. W. Walsh, "Failure of prophylactically administered phenytoin to prevent post-traumatic seizures in children," Child's Brain, vol. 10, no. 3, pp. 185-192, 1983.

[51] G. Teasdale and B. Jennett, "Assessment of coma and impaired consciousness. A practical scale," The Lancet, vol. 304, no. 7872, pp. 81-84, 1974.

[52] S. R. Beers, S. R. Wisniewski, P. Garcia-Filion et al., "Validity of a pediatric version of the glasgow outcome scale-extended," Journal of Neurotrauma, vol. 29, no. 6, pp. 1126-1139, 2012.

[53] C. Arienta, M. Caroli, and S. Balbi, "Management of headinjured patients in the emergency department: a practical protocol," Surgical Neurology, vol. 48, no. 3, pp. 213-219, 1997.

[54] R. Bullock, R. M. Chesnut, G. Clifton et al., "Guidelines for the management of severe head injury," European Journal of Emergency Medicine, vol. 3, no. 2, pp. 109-127, 1996.

[55] M. R. Bullock, R. Chesnut, J. Ghajar et al., "Surgical management of traumatic parenchymal lesions," Neurosurgery, vol. 58, supplement 3, pp. S25-S46, 2006.

[56] M. R. Bullock, R. Chesnut, J. Ghajar et al., "Surgical management of acute epidural hematomas," Neurosurgery, vol. 58, no. 3, pp. S7-S15, 2006.

[57] M. R. Bullock, R. Chesnut, J. Ghajar et al., "Surgical management of acute subdural hematomas," Neurosurgery, vol. 58, no. 3, pp. S216-S224, 2006.

[58] G. Baird, H. Cass, and V. Slonims, “Diagnosis of autism," British Medical Journal, vol. 327, no. 7413, pp. 488-493, 2003.

[59] P. A. Filipek, P. J. Accardo, S. Ashwal et al., "Practice parameter: screening and diagnosis of autism: report of the quality standards subcommittee of the American Academy of Neurology and the Child Neurology Society," Neurology, vol. 55, no. 4, pp. 468-479, 2000.

[60] S. Lanfranconi, G. Franco, L. Borellini et al., "Genetics of cerebral hemorrhage and microbleeds," Panminerva Medica, vol. 55, no. 1, pp. 11-28, 2013.
[61] K. Singh and A. W. Zimmerman, "Sleep in autism spectrum disorder and attention deficit hyperactivity disorder," Seminars in Pediatric Neurology, vol. 22, no. 2, pp. 113-125, 2015.

[62] C. S. Rosenfeld, "Microbiome disturbances and autism spectrum disorders," Drug Metabolism \& Disposition, vol. 43, no. 10, pp. 1557-1571, 2015.

[63] M. Carabotti, A. Scirocco, M. A. Maselli, and C. Severi, "The gut-brain axis: interactions between enteric microbiota, central and enteric nervous systems," Annals of Gastroenterology, vol. 28, no. 2, pp. 203-209, 2015.

[64] M. Douglas-Escobar, E. Elliott, and J. Neu, "Effect of intestinal microbial ecology on the developing brain," JAMA Pediatrics, vol. 167, no. 4, pp. 374-379, 2013.

[65] R. K. Naviaux, "Metabolic features of the cell danger response," Mitochondrion, vol. 16, pp. 7-17, 2014.

[66] K. Babinska, M. Bucova, V. Durmanova et al., "Increased plasma levels of the high mobility group box 1 protein (HMGB1) are associated with a higher score of gastrointestinal dysfunction in individuals with autism," Physiological Research, vol. 63, supplement 4, pp. S613-S618, 2014.

[67] M. Samsam, R. Ahangari, and S. A. Naser, "Pathophysiology of autism spectrum disorders: revisiting gastrointestinal involvement and immune imbalance," World Journal of Gastroenterology, vol. 20, no. 29, pp. 9942-9951, 2014.

[68] M. M. H. van De Sande, V. J. van Buul, and F. J. P. H. Brouns, "Autism and nutrition: the role of the gut-brain axis," Nutrition Research Reviews, vol. 27, no. 2, pp. 199-214, 2014.

[69] E. A. Mayer, D. Padua, and K. Tillisch, "Altered brain-gut axis in autism: comorbidity or causative mechanisms?" BioEssays, vol. 36, no. 10, pp. 933-939, 2014.

[70] A. P. Hill, J. van Santen, K. Gorman, B. H. Langhorst, and E. Fombonne, "Memory in language-impaired children with and without autism," Journal of Neurodevelopmental Disorders, vol. 7, article 19, 2015.

[71] H. B. Cygan, P. Tacikowski, P. Ostaszewski, I. Chojnicka, and A. Nowicka, "Neural correlates of own name and own face detection in autism spectrum disorder," PLoS ONE, vol. 9, no. 1, Article ID e86020, 2014.

[72] D. J. Greene, N. Colich, M. Iacoboni, E. Zaidel, S. Y. Bookheimer, and M. Dapretto, "Atypical neural networks for social orienting in autism spectrum disorders," NeuroImage, vol. 56, no. 1, pp. 354-362, 2011.

[73] P. Jedlicka, M. Vnencak, D. D. Krueger, T. Jungenitz, N. Brose, and S. W. Schwarzacher, "Neuroligin-1 regulates excitatory synaptic transmission, LTP and EPSP-spike coupling in the dentate gyrus in vivo," Brain Structure and Function, vol. 220, no. 1, pp. 47-58, 2015.

[74] T. J. Ornstein, S. Sagar, R. J. Schachar et al., "Neuropsychological performance of youth with secondary attentiondeficit/hyperactivity disorder 6- and 12-months after traumatic brain injury," Journal of the International Neuropsychological Society, vol. 20, no. 10, pp. 971-981, 2014.

[75] S. Gorman, M. A. Barnes, P. R. Swank, M. Prasad, and C. S. Cox, "Does processing speed mediate the effect of pediatric traumatic brain injury on working memory?" Neuropsychology, vol. 30, no. 3, pp. 263-273, 2016.

[76] R. Moretti, J. Pansiot, D. Bettati et al., "Blood-brain barrier dysfunction in disorders of the developing brain," Frontiers in Neuroscience, vol. 9, article 40, 2015.

[77] J. H. Coyne, J. M. Borg, J. Deluca, L. Glass, and J. F. Sumowski, "Retrieval practice as an effective memory strategy in children 
and adolescents with traumatic brain injury," Archives of Physical Medicine and Rehabilitation, vol. 96, no. 4, pp. 742-745, 2015.

[78] T. Aida, J. Yoshida, M. Nomura et al., "Astroglial glutamate transporter deficiency increases synaptic excitability and leads to pathological repetitive behaviors in mice," Neuropsychopharmacology, vol. 40, no. 7, pp. 1569-1579, 2015.

[79] M. R. Williams, T. De-Spenza Jr., M. Li, A. T. Gulledge, and B. W. Luikart, "Hyperactivity of newborn pten knock-out neurons results from increased excitatory synaptic drive," The Journal of Neuroscience, vol. 35, no. 3, pp. 943-959, 2015.

[80] K. Liesemer, S. L. Bratton, C. M. Zebrack, D. Brockmeyer, and K. D. Statler, "Early post-traumatic seizures in moderate to severe pediatric traumatic brain injury: rates, risk factors, and clinical features," Journal of Neurotrauma, vol. 28, no. 5, pp. 755-762, 2011.

[81] N. Golden, S. Darmadipura, and N. A. Bagiada, "The difference in seizure incidences between young and adult rats related to lipid peroxidation after intracortical injection of ferric chloride," Singapore Medical Journal, vol. 51, no. 2, pp. 105-109, 2010.

[82] M. S. Bessisso, M. F. El-Said, N. A. Almula, S. B. Azzam, H. A. Sweid, and M. G. Al-Ali, "Risk of seizure recurrences after first unprovoked seizure during childhood," Neurosciences, vol. 6, pp. 95-98, 2001.

[83] R. F. Hevner, "Brain overgrowth in disorders of RTK-PI3K-AKT signaling: a mosaic of malformations," Seminars in Perinatology, vol. 39, no. 1, pp. 36-43, 2015.

[84] P. B. Bernard and T. A. Benke, "Early life seizures: evidence for chronic deficits linked to autism and intellectual disability across species and models," Experimental Neurology, vol. 263, pp. 72-78, 2015.

[85] S. Budday, C. Raybaud, and E. Kuhl, "A mechanical model predicts morphological abnormalities in the developing human brain," Scientific Reports, vol. 4, article 5644, 2014.

[86] J. M. Baruth, M. F. Casanova, L. Sears, and E. Sokhadze, "EarlyStage visual processing abnormalities in high-functioning autism spectrum disorder (asd)," Translational Neuroscience, vol. 1, no. 2, pp. 177-187, 2010.

[87] M. F. Casanova, J. M. Baruth, A. El-Baz, A. Tasman, L. Sears, and E. Sokhadze, "Repetitive transcranial magnetic stimulation (rTMS) modulates event-related potential (ERP) indices of attention in autism," Translational Neuroscience, vol. 3, no. 2, pp. 170-180, 2012.

[88] T. P. L. Roberts, S. Y. Khan, M. Rey et al., "MEG detection of delayed auditory evoked responses in autism spectrum disorders: towards an imaging biomarker for autism," Autism Research, vol. 3, no. 1, pp. 8-18, 2010.

[89] W. Liao, M. J. Gandal, R. S. Ehrlichman, S. J. Siegel, and G. C. Carlson, "MeCP2+/- mouse model of RTT reproduces auditory phenotypes associated with Rett syndrome and replicate select EEG endophenotypes of autism spectrum disorder," Neurobiology of Disease, vol. 46, pp. 88-92, 2012.

[90] T. M. DeLorey, P. Sahbaie, E. Hashemi, W.-W. Li, A. Salehi, and D. J. Clark, "Somatosensory and sensorimotor consequences associated with the heterozygous disruption of the autism candidate gene, Gabrb3," Behavioural Brain Research, vol. 216, no. 1, pp. 36-45, 2011.

[91] N. Li, Y. Yang, D. P. Glover et al., "Evidence for impaired plasticity after traumatic brain injury in the developing brain," Journal of Neurotrauma, vol. 31, no. 4, pp. 395-403, 2014.

[92] J. Galvin, E. H. Froude, and C. Imms, "Sensory processing abilities of children who have sustained traumatic brain injuries,"
American Journal of Occupational Therapy, vol. 63, no. 6, pp. 701-709, 2009.

[93] E. Glerean, R. K. Pan, J. Salmi et al., "Reorganization of functionally connected brain subnetworks in high-functioning autism," Human Brain Mapping, vol. 37, no. 3, pp. 1066-1079, 2016.

[94] U. Roine, T. Roine, J. Salmi et al., "Abnormal wiring of the connectome in adults with high-functioning autism spectrum disorder," Molecular Autism, vol. 6, article 65, 2015.

[95] C. C. Dougherty, D. W. Evans, S. M. Myers, G. J. Moore, and A. M. Michael, "A comparison of structural brain imaging findings in autism spectrum disorder and attention-deficit hyperactivity disorder," Neuropsychology Review, vol. 26, no. 1, pp. 25-43, 2016.

[96] S. C. L. Deoni, J. R. Zinkstok, E. Daly et al., "White-matter relaxation time and myelin water fraction differences in young adults with autism," Psychological Medicine, vol. 45, no. 4, pp. 795-805, 2015.

[97] M. Lazar, L. M. Miles, J. S. Babb, and J. B. Donaldson, "Axonal deficits in young adults with high functioning autism and their impact on processing speed," NeuroImage: Clinical, vol. 4, pp. 417-425, 2014.

[98] L. Cerliani, M. Mennes, R. M. Thomas, A. Di Martino, M. Thioux, and C. Keysers, "Increased functional connectivity between subcortical and cortical resting-state networks in Autism spectrum disorder," JAMA Psychiatry, vol. 72, no. 8, pp. 767-777, 2015.

[99] E. L. Dennis, Y. Jin, J. E. Villalon-Reina et al., "White matter disruption in moderate/severe pediatric traumatic brain injury: advanced tract-based analyses," NeuroImage: Clinical, vol. 7, pp. 493-505, 2015.

[100] P. Kourtidou, S. R. McCauley, E. D. Bigler et al., "Centrum semiovale and corpus callosum integrity in relation to information processing speed in patients with severe traumatic brain injury," Journal of Head Trauma Rehabilitation, vol. 28, no. 6, pp. 433-441, 2013.

[101] B. L. Bartnik-Olson, B. Holshouser, H. Wang et al., "Impaired neurovascular unit function contributes to persistent symptoms after concussion: a pilot study," Journal of Neurotrauma, vol. 31, no. 17, pp. 1497-1506, 2014.

[102] T. C. Wu, E. A. Wilde, E. D. Bigler et al., "Longitudinal changes in the corpus callosum following pediatric traumatic brain injury," Developmental Neuroscience, vol. 32, no. 5-6, pp. 361373, 2011.

[103] J. V. Hunter, E. A. Wilde, K. A. Tong, and B. A. Holshouser, "Emerging imaging tools for use with traumatic brain injury research," Journal of Neurotrauma, vol. 29, no. 4, pp. 654-671, 2012.

[104] M. H. Beauchamp, R. Beare, M. Ditchfield et al., "Susceptibility weighted imaging and its relationship to outcome after pediatric traumatic brain injury," Cortex, vol. 49, no. 2, pp. 591-598, 2013.

[105] S. J. Suskauer and T. A. G. M. Huisman, "Neuroimaging in pediatric traumatic brain injury: current and future predictors of functional outcome," Developmental Disabilities Research Reviews, vol. 15, no. 2, pp. 117-123, 2009.

[106] M. Königs, W. D. Weeda, L. W. E. van Heurn et al., "Impaired visual integration in children with traumatic brain injury: an observational study," PLOS ONE, vol. 10, no. 12, Article ID e0144395, 2015. 
[107] F. K. Korley, R. Diaz-Arrastia, A. H. B. Wu et al., "Circulating brain-derived neurotrophic factor has diagnostic and prognostic value in traumatic brain injury," Journal of Neurotrauma, vol. 33, no. 2, pp. 215-225, 2016.

[108] D. Granpeesheh, J. Tarbox, and D. R. Dixon, "Applied behavior analytic interventions for children with autism: a description and review of treatment research," Annals of Clinical Psychiatry, vol. 21, no. 3, pp. 162-173, 2009.

[109] M. L. Sundberg and J. Michael, "The benefits of Skinner's analysis of verbal behavior for children with autism," Behavior Modification, vol. 25, no. 5, pp. 698-724, 2001.

[110] D. M. Baer, M. M. Wolf, and T. R. Risley, "Some current dimensions of applied behavior analysis," Journal of Applied Behavior Analysis, vol. 1, no. 1, pp. 91-97, 1968.

[111] L. Y. Tsai, "Brief report: comorbid psychiatric disorders of autistic disorder," Journal of Autism and Developmental Disorders, vol. 26, no. 2, pp. 159-163, 1996.

[112] M. L. Sundberg, B. S. Juan, M. Dawdy, and M. Arguelles, "The acquisition of tacts, mands, and intraverbals by individuals with traumatic brain injury," The Analysis of Verbal Behavior, vol. 8, pp. 83-99, 1990.

[113] A. M. Steiner, G. W. Gengoux, A. Klin, and K. Chawarska, "Pivotal response treatment for infants at-risk for autism spectrum disorders: a pilot study," Journal of Autism and Developmental Disorders, vol. 43, no. 1, pp. 91-102, 2013.

[114] F. Mohammadzaheri, L. K. Koegel, M. Rezaei, and E. Bakhshi, "A randomized clinical trial comparison between Pivotal Response Treatment (PRT) and adult-driven Applied Behavior Analysis (ABA) intervention on disruptive behaviors in public school children with autism," Journal of Autism and Developmental Disorders, vol. 45, no. 9, pp. 2899-2907, 2015.

[115] M. Ylvisaker, L. Turkstra, C. Coehlo et al., "Behavioural interventions for children and adults with behaviour disorders after TBI: a systematic review of the evidence," Brain Injury, vol. 21, no. 8, pp. 769-805, 2007.

[116] S. L. Wade, H. G. Taylor, A. Cassedy et al., "Long-term behavioral outcomes after a randomized, clinical trial of counselorassisted problem solving for adolescents with complicated mildto-severe traumatic brain injury," Journal of Neurotrauma, vol. 32, no. 13, pp. 967-975, 2015.

[117] J. L. Matson and J. Jang, "Treating aggression in persons with autism spectrum disorders: a review," Research in Developmental Disabilities, vol. 35, no. 12, pp. 3386-3391, 2014.

[118] G. Dawson and R. Bernier, "A quarter century of progress on the early detection and treatment of autism spectrum disorder," Development and Psychopathology, vol. 25, no. 4, pp. 1455-1472, 2013.

[119] S. Q. Mehta and P. Golshani, "Clinical neurogenetics: autism spectrum disorders," Neurologic Clinics, vol. 31, no. 4, pp. 951968, 2013.

[120] C. Farmer, A. Thurm, and P. Grant, "Pharmacotherapy for the core symptoms in autistic disorder: current status of the research," Drugs, vol. 73, no. 4, pp. 303-314, 2013.

[121] M. L. McPheeters, Z. Warren, N. Sathe et al., "A systematic review of medical treatments for children with autism spectrum disorders," Pediatrics, vol. 127, no. 5, pp. e1312-e1321, 2011.

[122] P. A. J. Janssen, C. J. E. Niemegeers, F. Awouters, K. H. L. Schellekens, A. A. H. P. Megens, and T. F. Meert, "Pharmacology of risperidone (R 64766 ), a new antipsychotic with serotoninS2 and dopamine-D2 antagonistic properties," Journal of Pharmacology and Experimental Therapeutics, vol. 244, no. 2, pp. 685-693, 1988.
[123] J. E. Leysen, W. Gommeren, A. Eens, D. De Chaffoy de Courcelles, J. C. Stoof, and P. A. J. Janssen, "Biochemical profile of risperidone, a new antipsychotic," Journal of Pharmacology and Experimental Therapeutics, vol. 247, no. 2, pp. 661-670, 1988.

[124] O. S. Jesner, M. Aref-Adib, and E. Coren, "Risperidone for autism spectrum disorder," Cochrane Database of Systematic Reviews, no. 1, Article ID CD005040, 2007.

[125] J. T. McCracken, J. McGough, B. Shah et al., "Risperidone in children with autism and serious behavioral problems," The New England Journal of Medicine, vol. 347, no. 5, pp. 314-321, 2002.

[126] C. J. McDougle, L. Scahill, M. G. Aman et al., "Risperidone for the core symptom domains of autism: results from the study by the Autism Network of the Research Units on Pediatric Psychopharmacology," American Journal of Psychiatry, vol. 162, no. 6, pp. 1142-1148, 2005.

[127] S. Shea, A. Turgay, A. Carroll et al., "Risperidone in the treatment of disruptive behavioral symptoms in children with autistic and other pervasive developmental disorders," Pediatrics, vol. 114, no. 5, pp. e634-e641, 2004.

[128] D. A. Shapiro, S. Renock, E. Arrington et al., "Aripiprazole, a novel atypical antipsychotic drug with a unique and robust pharmacology," Neuropsychopharmacology, vol. 28, no. 8, pp. 1400-1411, 2003.

[129] P. J. Goodnick and J. M. Jerry, "Aripiprazole: profile on efficacy and safety," Expert Opinion on Pharmacotherapy, vol. 3, no. 12, pp. 1773-1781, 2002.

[130] C. A. Farmer and M. G. Aman, "Aripiprazole for the treatment of irritability associated with autism," Expert Opinion on Pharmacotherapy, vol. 12, no. 4, pp. 635-640, 2011.

[131] H. Ching and T. Pringsheim, Aripiprazole for Autism Spectrum Disorders (ASD), The Cochrane Library, 2012.

[132] Y.-C. Chang, J. Quan, and J. J. Wood, "Effects of anxiety disorder severity on social functioning in children with autism spectrum disorders," Journal of Developmental and Physical Disabilities, vol. 24, no. 3, pp. 235-245, 2012.

[133] J. J. Wood and K. D. Gadow, "Exploring the nature and function of anxiety in youth with autism spectrum disorders," Clinical Psychology: Science and Practice, vol. 17, no. 4, pp. 281-292, 2010.

[134] B. Bandelow, U. Seidler-Brandler, A. Becker, D. Wedekind, and E. Rüther, "Meta-analysis of randomized controlled comparisons of psychopharmacological and psychological treatments for anxiety disorders," The World Journal of Biological Psychiatry, vol. 8, no. 3, pp. 175-187, 2007.

[135] G. M. Soomro, D. Altman, S. Rajagopal, and M. OakleyBrowne, "Selective serotonin re-uptake inhibitors (SSRIs) versus placebo for obsessive compulsive disorder (OCD)," The Cochrane Database of Systematic Reviews, no. 1, Article ID CD001765, 2008.

[136] E. H. Cook Jr. and B. L. Leventhal, "The serotonin system in autism," Current Opinion in Pediatrics, vol. 8, no. 4, pp. 348-354, 1996.

[137] B. Devlin, E. H. Cook Jr., H. Coon et al., "Autism and the serotonin transporter: the long and short of it," Molecular Psychiatry, vol. 10, no. 12, pp. 1110-1116, 2005.

[138] S. E. Maloney, M. A. Rieger, and J. D. Dougherty, "Identifying essential cell types and circuits in autism spectrum disorders," International Review of Neurobiology, vol. 113, pp. 61-96, 2013.

[139] A. Oblak, T. T. Gibbs, and G. J. Blatt, "Reduced serotonin receptor subtypes in a limbic and a neocortical region in autism," Autism Research, vol. 6, no. 6, pp. 571-583, 2013. 
[140] M. Carrasco, F. R. Volkmar, and M. H. Bloch, "Pharmacologic treatment of repetitive behaviors in autism spectrum disorders: evidence of publication bias," Pediatrics, vol. 129, no. 5, pp. e1301-e1310, 2012.

[141] A. Kolevzon, K. A. Mathewson, and E. Hollander, "Selective serotonin reuptake inhibitors in autism: a review of efficacy and tolerability," Journal of Clinical Psychiatry, vol. 67, no. 3, pp. 407414, 2006.

[142] P. R. Choudhury, S. Lahiri, and U. Rajamma, "Glutamate mediated signaling in the pathophysiology of autism spectrum disorders," Pharmacology Biochemistry and Behavior, vol. 100, no. 4, pp. 841-849, 2012.

[143] S. Coghlan, J. Horder, B. Inkster, M. A. Mendez, D. G. Murphy, and D. J. Nutt, "GABA system dysfunction in autism and related disorders: from synapse to symptoms," Neuroscience \& Biobehavioral Reviews, vol. 36, no. 9, pp. 2044-2055, 2012.

[144] M. M. Lim, I. F. Bielsky, and L. J. Young, "Neuropeptides and the social brain: potential rodent models of autism," International Journal of Developmental Neuroscience, vol. 23, no. 2-3, pp. 235243, 2005.

[145] C. Modahl, L. Green, D. Fein et al., "Plasma oxytocin levels in autistic children," Biological Psychiatry, vol. 43, no. 4, pp. $270-$ 277, 1998.

[146] K. B. Nelson, J. K. Grether, L. A. Croen et al., "Neuropeptides and neurotrophins in neonatal blood of children with autism or mental retardation," Annals of Neurology, vol. 49, no. 5, pp. 597-606, 2001.

[147] S. I. Deutsch, M. R. Urbano, S. A. Neumann, J. A. Burket, and E. Katz, "Cholinergic abnormalities in autism: is there a rationale for selective nicotinic agonist interventions?" Clinical Neuropharmacology, vol. 33, no. 3, pp. 114-120, 2010.

[148] P. M. Lippiello, "Nicotinic cholinergic antagonists: a novel approach for the treatment of autism," Medical Hypotheses, vol. 66, no. 5, pp. 985-990, 2006.

[149] K. Beauchamp, H. Mutlak, W. R. Smith, E. Shohami, and P. F. Stahel, "Pharmacology of traumatic brain injury: where is the "golden bullet"?" Molecular Medicine, vol. 14, no. 11-12, pp. 731$740,2008$.

[150] E. Chew and R. D. Zafonte, "Pharmacological management of neurobehavioral disorders following traumatic brain injury-a state-of-the-art review," Journal of Rehabilitation Research and Development, vol. 46, no. 6, pp. 851-878, 2009.

[151] D. J. Loane and A. I. Faden, "Neuroprotection for traumatic brain injury: translational challenges and emerging therapeutic strategies," Trends in Pharmacological Sciences, vol. 31, no. 12, pp. 596-604, 2010.

[152] M. G. Aman, C. J. McDougle, L. Scahill et al., "Medication and parent training in children with pervasive developmental disorders and serious behavior problems: results from a randomized clinical trial," Journal of the American Academy of Child and Adolescent Psychiatry, vol. 48, no. 12, pp. 1143-1154, 2009.

[153] S. Margulies and R. Hicks, "The combination therapies for traumatic brain injury workshop l: combination therapies for traumatic brain injury: prospective considerations," Journal of Neurotrauma, vol. 26, no. 6, pp. 925-939, 2009. 


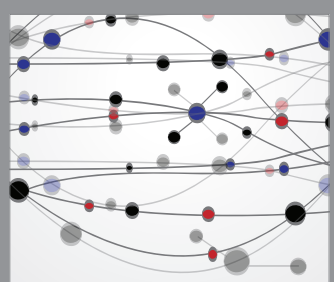

The Scientific World Journal
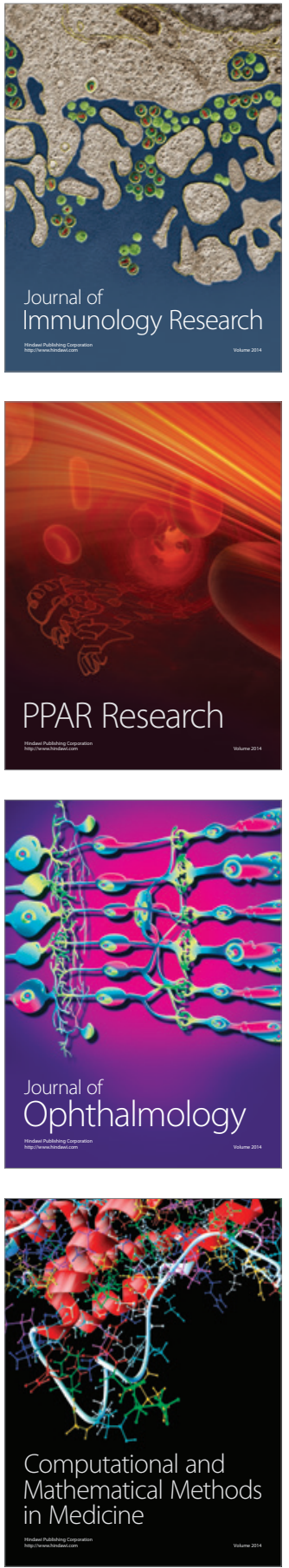

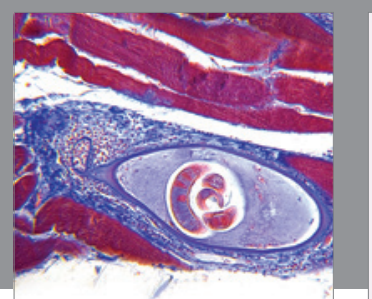

Gastroenterology Research and Practice

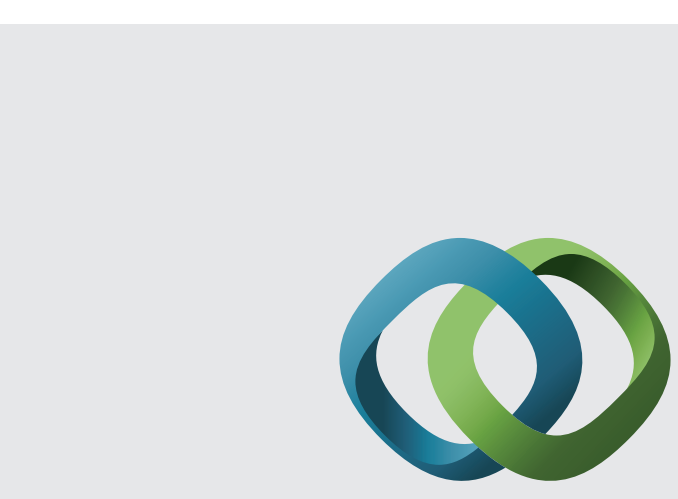

\section{Hindawi}

Submit your manuscripts at

http://www.hindawi.com
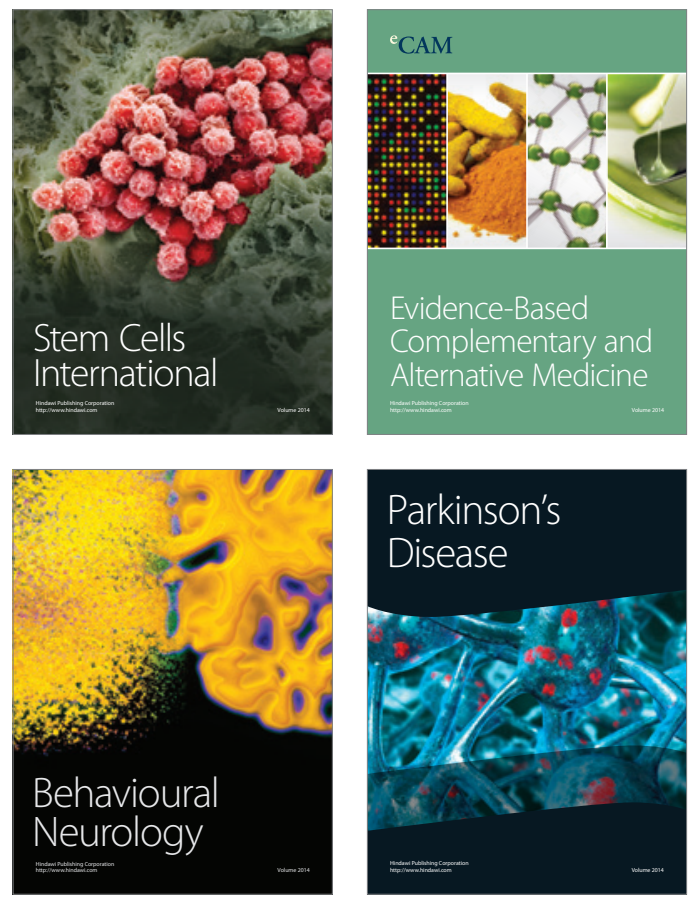
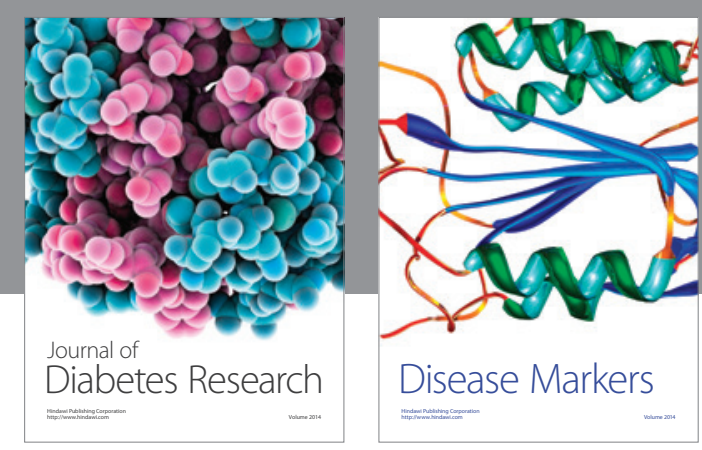

Disease Markers
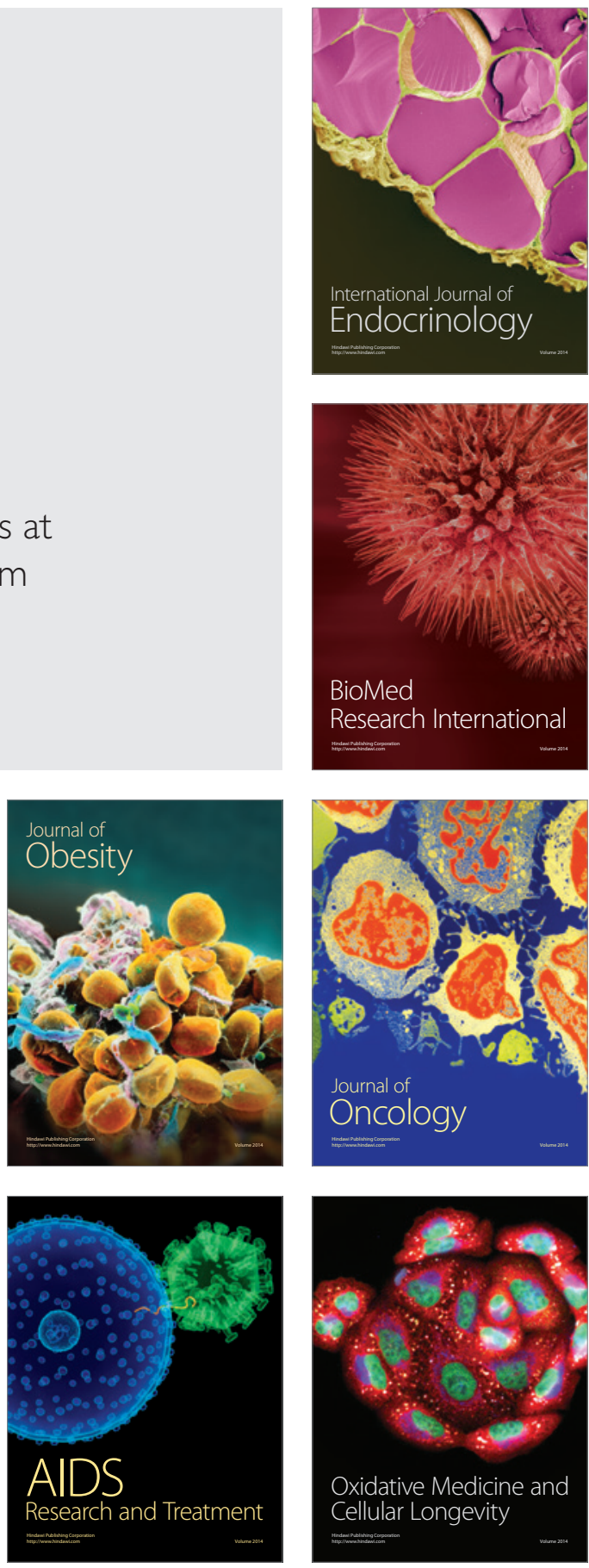